\title{
EVALUATE OF TWO DIFFERENT METHODS IN CLOSE RANGE PHOTOGRAMMETRY FOR DETERMINATION 3-D COORDINATE APPLIED TO VERTICALITY CHECKING
}

\author{
Abo El Hassan M.Rahil ${ }^{*}$ \\ Hisham Abou Halima** \\ *Associate Prof, faculty of Eng.,Shebin El-Kom,Minufiya University,Egypt. \\ ${ }^{* *}$ Assistant Prof, faculty of Eng., El-Mansora, El-Mansora University, Egypt.
}

\begin{abstract}
There are many ways to construct object -space coordinates, each is designed for a certain purpose. In this research, a comparison between two different methods, in close range photogrammetry was carried out, in order to find, the more accurate, simpler and more economic method. The accuracy in each method was determined by comparing its coordinates with the coordinates of the test field, which were calculated from the intersection method.
\end{abstract}

\section{INTRODUCTION}

Engineering surveyors are often required to monitor the inclination and the direction of tilt of structures. The plum bob and spirit level are considered to be the easiest and most efficient instrument used in most cases. However, when the structure is inaccessible, it is not possible to utilize these methods. For determining the three dimensional coordinates of points, which are difficult or impossible to access, there are many different methods, which can be used for these purposes. This paper presents, discusses and compares between two different methods. The first method, is the pseudo image, it is a different technique for the geodetic coordination of object-space controls in close-range photogrammetry method. The second method is an alternative approach for solving the space intersection problem in close range photogrammetry. 
At the faculty of Engineering Shebin El-Kom, there is one reference point network, this reference point is a vertical plane forming the test wall. The dimensions are $15^{*} 11$ meters (Fig. 1).

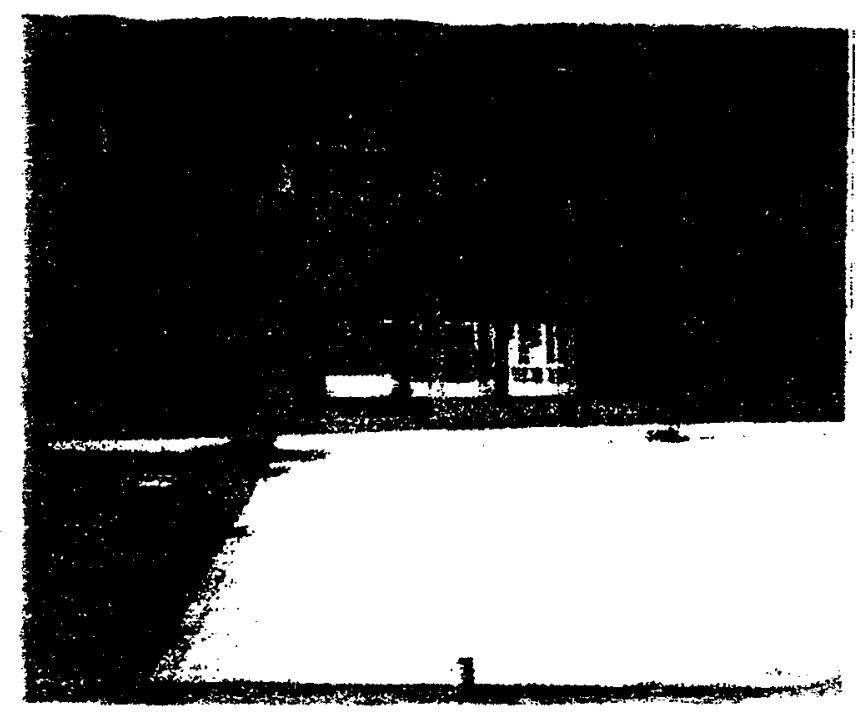

Fig(1) The test field and the reference points network by using the metric camera UMK10/1318

The wall is constructed for an object distance of the range of about 6 to 25 metros. The reference point network consists of 36-fixed black-and white circular shaped targets (Fig.2). The intersection method by two theodolite stations was used to compute the coordinates of the control and check points, which are needed for the orientation of the photographed object and for evaluation of the accuracy of the two different methods. In this research, the intersection method is used as a comparable method to compare between the results obtained from two different methods (the pseudo image and the proposed technique).

The above mentioned test field, using the intersection method, has been characterized by the following RMS errors: $0.23 \mathrm{~mm}$ for the X-axis; 0.28 ; $0.23 \mathrm{~mm}$ for the $\mathrm{Y}$-axis and $0.21 \mathrm{~mm}$ for the $\mathrm{Z}$-axis.

In this method two observation stations ( $A$ and $B$ ) are fastened in the front of the test field. Fig. (2) shows the targets, which are fixed on the vertical wall in the front of the two observation stations ( $A$ and $B$ ). Line $A B$ was taken as a base line, where horizontal angles between that line and rays to the intersected targets on the test field were measured. One-second theodolite (Theo-10-A) from Zeis Jena was used for the angles measurement. The length of the base line $\mathrm{AB}$ was measured by a steel tape with an accuracy of $\pm 0.5 \mathrm{~mm}$. The horizontal and vertical angles were measured twice with the theodolite face left and face right with the zero reading being changed each time and the mean values of the measured angles were computed. Rays to the targets were determined using the base line $(A B)$ and the obtained 
horizontal angles. The coordinates of all targets of the test field were calculated.

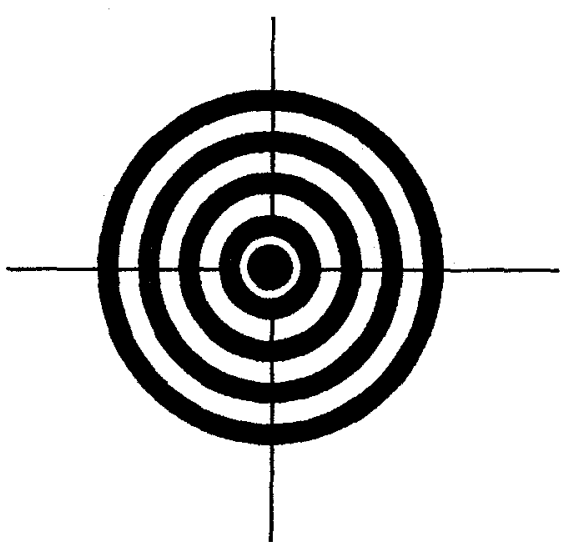

Fig. 2 The Target

\section{THE PSEUDO IMAGE METHOD}

A different method for the geodetic coordination of object space controls in close - range photogrammetry has been proposed by Abdel Aziz and Karara (1974) . In the pseudo image method the theodolite is used instead of the camera for taking the photograph and also is used instead of the comparator for image coordinate measurements.

The advantages of the pseudo image method are that:

-One needs only a theodolite for measurements and a simple calculator for data reduction.

-The resulting accuracy is better than that obtained by using the proposed technique and is comparable with the accuracy of the intersection method.

-No need for development and processing.

-No need for a comparator to measure the image coordinates.

-One can reach the required accuracy for measuring the image coordinates by using small scale.

-In the pseudo image there is no limitations on the format size, the depth of field and the intensity of light.

The principal of the pseudo image method consists of three successive steps:

a- Recording from two (or more) stations the perspective bundles with a theodolite used as a camera in the test area .

b- Relative orientation of the images and computation of the model coordinates of the points.

c- Scaling the model is necessary if the computed coordinates are to be used as an object-space control for data reduction. 
For more detail, the reader is referred to Abdel Aziz and Karara (19/4). Io verify the pseudo image method, two observation stations ( $A$ and $B$ ) in front of the test field were used as a theodolite station. The horizontal and vertical directions to all targets from the two theodolite stations ( $A$ and $B$ ) were observed by one -second theodolite Theo 10-A from Jena ). In this work, the test field (Fig. 1) consists of 36 points and three different calibrated distances were observed. In this technique, the theodolite images are formed analytically from theodolite measurements. The pseudo - image coordinates in a convergent imaging configuration $\left(\omega_{1}=\omega_{2}=0.0 \& \kappa_{1}=\kappa_{2}=0.0 \& \varphi_{1}=\right.$ $\varphi_{1}=42^{\circ}$ ) of all targets in the pseudo image plane of the horizontal circle can be calculated as follows :

$$
\begin{aligned}
& x=C_{k} \tan \left(90-\alpha_{0}+\alpha\right) \\
& z=C_{k} \tan \beta / \cos \left(90-\alpha_{0}+\alpha\right)
\end{aligned}
$$

where :

$\alpha_{0}$ is the horizontal direction of the other station;

$\mathrm{x}$ and $\mathrm{z}$ are the theodolite image coordinates;

$\mathrm{C}_{\mathrm{k}}$ is the camera constant;

$\beta$ is the vertical direction of the target.

The theodolite observations and the virtual image coordinates are listed in tables 1 and 2. The object space coordinates can be obtained with an origin at the perspective center of the left station, the $X$ axis parallel to the given $X$ axis, and the $Z$ axis a vertical line parallel to the plump bob direction at the origin. The object space coordinates can be obtained by using the values of the relative orientation parameters and the exact values of $B_{X}$ and $B_{Z}$. The object space coordinates of the test field targets are listed in table 3 .

TABLE (1) THEODOLITE OBSERVATIONS AND VIRTUAL IMAGE COORDINATES AT THE LEFT STATION (A).

\begin{tabular}{|c|c|c|c|c|}
\hline \multicolumn{9}{|c|}{$\alpha_{0} 136^{\circ} 05^{\circ} 35$} & \multicolumn{2}{c|}{ Image coordinate } \\
\hline $\begin{array}{c}\text { Pt. } \\
\text { N.o }\end{array}$ & $\begin{array}{c}\text { Horizontal } \\
\text { directions }(\alpha)\end{array}$ & $\begin{array}{c}\text { Vertical } \\
\text { directions }(\beta)\end{array}$ & $\begin{array}{c}\text { xl } \\
\mathrm{mm}\end{array}$ & $\begin{array}{c}\mathrm{zl} \\
\mathrm{mm}\end{array}$ \\
\hline 1 & $38^{\circ} 0440^{\circ}$ & $71^{\circ} 3530^{\circ}$ & -14.081 & 33.610 \\
\hline 2 & 381620 & 752920 & -13.735 & 26.125 \\
\hline 3 & 381330 & 823320 & -13.819 & 13.191 \\
\hline 4 & 520455 & 710650 & 10.491 & 34.398 \\
\hline 5 & 520220 & 754535 & 10.415 & 25.516 \\
\hline 6 & 515210 & 830700 & 10.116 & 12.133 \\
\hline 7 & 660130 & 720110 & 36.263 & 34.522 \\
\hline 8 & 660020 & 762820 & 36.224 & 25.589 \\
\hline 9 & 655405 & 832740 & 36.019 & 12.183 \\
\hline 10 & 775305 & 734015 & 61.983 & 34.469 \\
\hline 11 & 775615 & 774310 & 62.110 & 25.625 \\
\hline 12 & 773940 & 842040 & 61.444 & 11.623 \\
\hline 13 & 502740 & 843520 & 7.639 & 9.499 \\
\hline 14 & 493720 & 851410 & 6.167 & 8.350 \\
\hline 15 & 602920 & 844815 & 25.668 & 9.388 \\
\hline 16 & 592430 & 852150 & 23.667 & 8.333 \\
\hline 17 & 242520 & 520605 & -39.736 & 83.764 \\
\hline 18 & 231625 & 715030 & -42.076 & 35.583 \\
\hline
\end{tabular}




\begin{tabular}{|l|l|l|l|l|}
\hline 19 & 302310 & 712605 & -28.122 & 34.889 \\
\hline 20 & 444810 & 705010 & -2.252 & 34.762 \\
\hline 21 & 590920 & 711805 & 23.202 & 34.744 \\
\hline 22 & 720840 & 724125 & 48.884 & 34.690 \\
\hline 23 & 1030115 & 890225 & 153.562 & 3.070 \\
\hline
\end{tabular}

TABLE (2) THEODOLITE OBSERVATIONS AND VIRTUAL IMAGE COORDINATES AT THE RIGHT STATION (B ).

\begin{tabular}{|c|c|c|c|c|}
\hline \multicolumn{9}{|c|}{$\alpha_{0} 145^{\circ} 26^{\circ} 05^{\circ}$} & \multicolumn{2}{c|}{ Image coordinate } \\
\hline $\begin{array}{c}\text { Pt. } \\
\text { N.o }\end{array}$ & $\begin{array}{c}\text { Horizontal directions } \\
(\alpha)\end{array}$ & $\begin{array}{c}\text { Vertical } \\
\text { directions }(\beta)\end{array}$ & $\begin{array}{c}\mathrm{xr} \\
\mathbf{m m}\end{array}$ & $\begin{array}{c}\mathrm{zr} \\
\mathrm{mm}\end{array}$ \\
\hline 1 & $97^{\circ} 55^{\circ} 45^{\circ}$ & $76^{\circ} 10^{\circ} 40^{\circ}$ & -91.615 & 33.368 \\
\hline 2 & 980025 & 971235 & -91.865 & 25.880 \\
\hline 3 & 980305 & 843330 & -92.008 & 12.945 \\
\hline 4 & 891140 & 740850 & -66.842 & 34.156 \\
\hline 5 & 892810 & 781020 & -67.539 & 25.271 \\
\hline 6 & 891940 & 842145 & -67.180 & 11.892 \\
\hline 7 & 774135 & 722340 & -40.928 & 34.287 \\
\hline 8 & 775955 & 764935 & -41.552 & 25.385 \\
\hline 9 & 774630 & 831755 & -41.095 & 11.939 \\
\hline 10 & 635750 & 711755 & -14.997 & 34.229 \\
\hline 11 & 641500 & 755505 & -15.508 & 25.385 \\
\hline 12 & 641210 & 831410 & -15.424 & 12.001 \\
\hline 13 & 810435 & 851150 & -48.001 & 9.32 \\
\hline 14 & 785130 & 854205 & -43.323 & 8.192 \\
\hline 15 & 720300 & 847525 & -29.840 & 9.209 \\
\hline 16 & 695110 & 852820 & -25.709 & 8.177 \\
\hline 17 & 1050410 & 620935 & -117.644 & 81.546 \\
\hline 18 & 1053705 & 771540 & -119.953 & 35.306 \\
\hline 19 & 1015635 & 763510 & -105.409 & 34.652 \\
\hline 20 & 934510 & 745055 & -79.026 & 34.513 \\
\hline 21 & $83 \quad 3430$ & 730435 & -53.485 & 34.506 \\
\hline 22 & 705220 & 713800 & -27.615 & 34.444 \\
\hline 23 & 1264555 & 894520 & -295.957 & 1.333 \\
\hline
\end{tabular}

TABLE (3) COORDINATES OF THE TARGETS OBTAINED BY USING THE VIRTUAL IMAGE.

\begin{tabular}{|c|c|c|c|}
\hline Pf NO & \multicolumn{3}{|c|}{ Coordinates } \\
\hline 1 & $\mathrm{X}$ & $\mathrm{Y}$ & $\mathrm{Z}$ \\
\hline 2 & -2.1744 & 15.4421 & 6.8421 \\
\hline 3 & -2.1048 & 15.3243 & 5.6556 \\
\hline+ & -2.1161 & 15.3127 & 3.6718 \\
\hline 5 & 1.6242 & 15.4822 & 6.9776 \\
\hline 6 & 1.5996 & 15.3589 & 5.5709 \\
\hline 7 & 1.5669 & 15.4897 & 3.5314 \\
\hline 8 & 5.6246 & 15.5108 & 7.0067 \\
\hline 9 & 5.5763 & 15.3940 & 5.5911 \\
\hline 10 & 5.5923 & 15.5262 & 3.5435 \\
\hline & 9.6403 & 15.5533 & 7.0130 \\
\hline
\end{tabular}




\begin{tabular}{|l|l|l|l|}
\hline 11 & 9.5807 & 15.4253 & 5.6047 \\
\hline 12 & 9.5704 & 15.5760 & 3.4624 \\
\hline 13 & 1.6436 & 21.5185 & 3.6962 \\
\hline 14 & 1.49204 & 24.1924 & 3.6719 \\
\hline 15 & 5.5364 & 21.5695 & 3.6769 \\
\hline 16 & 5.7388 & 24.2482 & 3.6726 \\
\hline 17 & -6.1065 & 15.3679 & 14.5248 \\
\hline 18 & -6.4688 & 15.3741 & 7.1225 \\
\hline 19 & -4.3564 & 15.4915 & 7.0568 \\
\hline 20 & -0.3521 & 15.5949 & 7.0731 \\
\hline 21 & 3.6224 & 15.6126 & 7.0765 \\
\hline 22 & 7.6508 & 15.6509 & 7.0812 \\
\hline 23 & 4.0901 & 2.6634 & 1.7337 \\
\hline
\end{tabular}

\section{THE PROPOSED TECHNIQUE}

\subsection{THE THEORETICAL ASPECTS}

Rahil [2000]proposed an alternative approach for the problem of the space intersection in close range photogrammetry. When compared with the conventional close-range photogrammetry technique, the proposed method is more accurate ,simpler and economic [18].

The advantages of this approach are as follows:

-Using single camera instead of stereo metric camera, to obtain stereo pairs, by exposing single photos at the ends of a measured base line.

-Choosing the suitable base-depth ratio, which gives geometric strength;

-There is no geometric problem, when the photographed object lies in one plane;

- The expected accuracy of the object space coordinates is better than that obtained by using the conventional analytical photogrammetric technique;

-Saving the required time for linear measurements and for control points establishments

The principal of the proposed technique consists of the following steps:

a)Construction of two or more photos of the test area;

b) Relative oriention of the images and computation of the model coordinates of the points;

c) Scaling the model is necessary if computed coordinates are to be used as an object-space control

In this study, we will be dealing with the symmetric convergent case $\left(\Phi_{\mathrm{L}}=\right.$ $\left.\Phi_{\mathrm{R}}=\Phi\right)$. For the simplicity and convenience work, photos would be arranged so, that the horizontal fiducial line in each photo stays horizontal while the vertical fiducial line in each photo remains vertical. 
By investigating the relative orientation parameters which are required to orient the right photo with respect to the left photo one finds that:

-Two orientation parameters of the two photos are known, having zero values; because:

a) The $Z$ - axes of the two photos, which is parallel to the plumb line are parallel $\left(\kappa_{1}=\kappa_{2}=0.0\right)$.

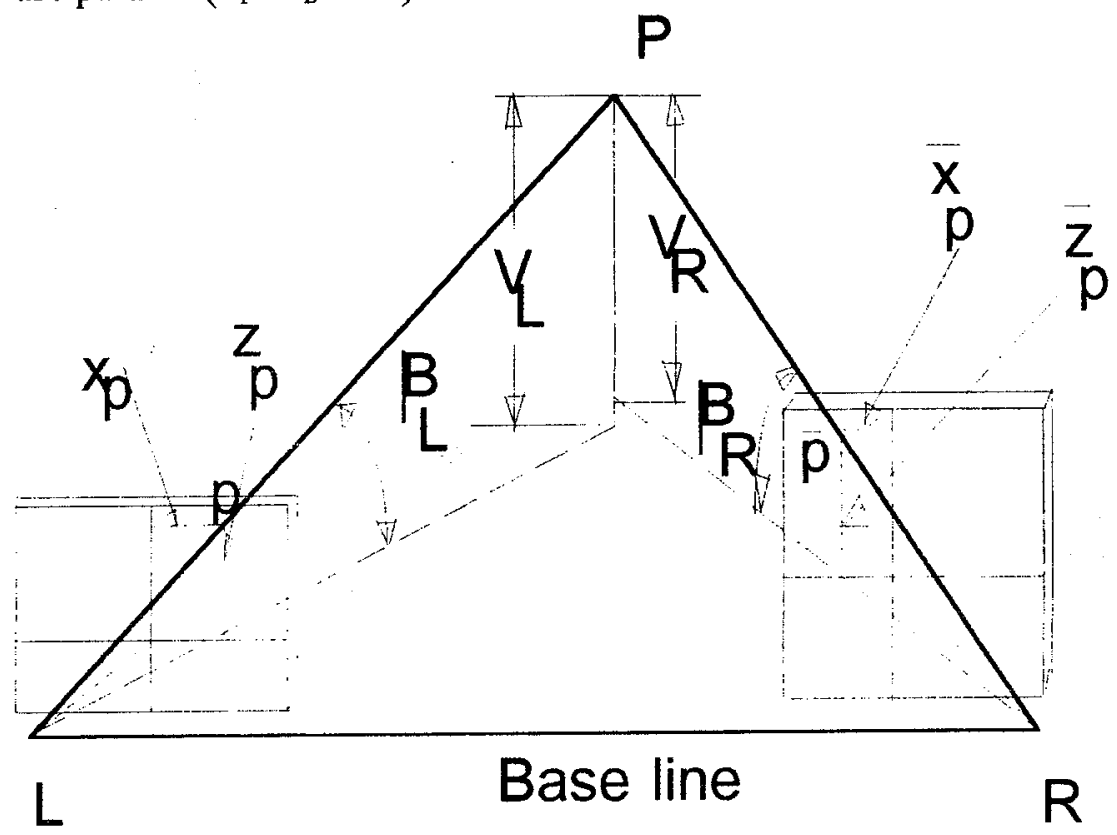

Fig. (3.a) Elevation of points from two horizontal photos.

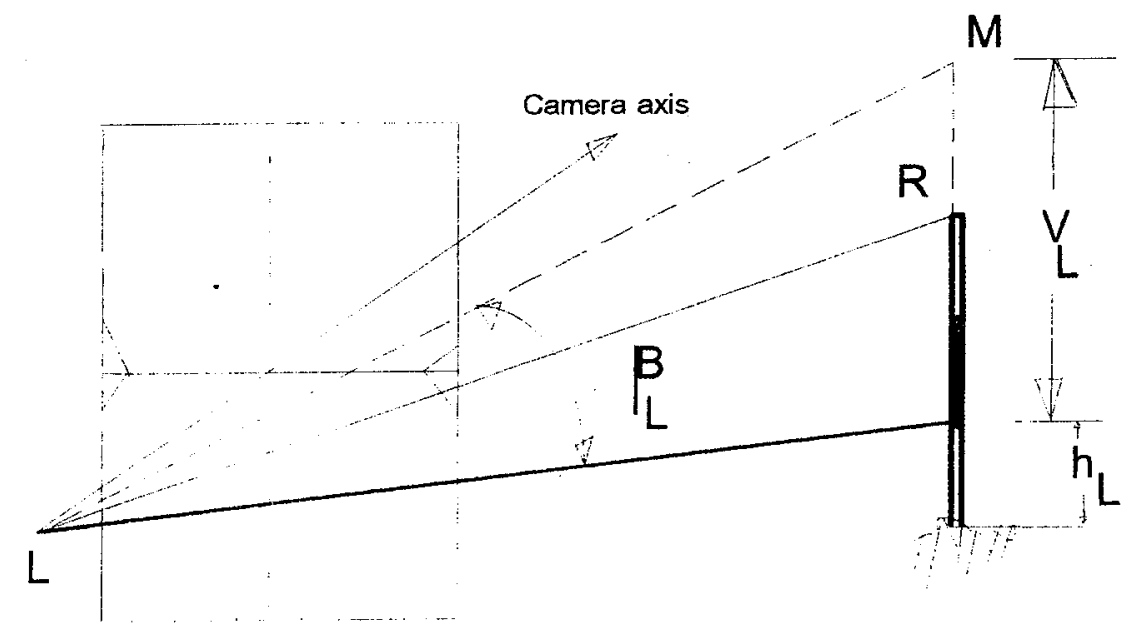

Fig. (3.b) Elevation of points at the left exposure stations. 


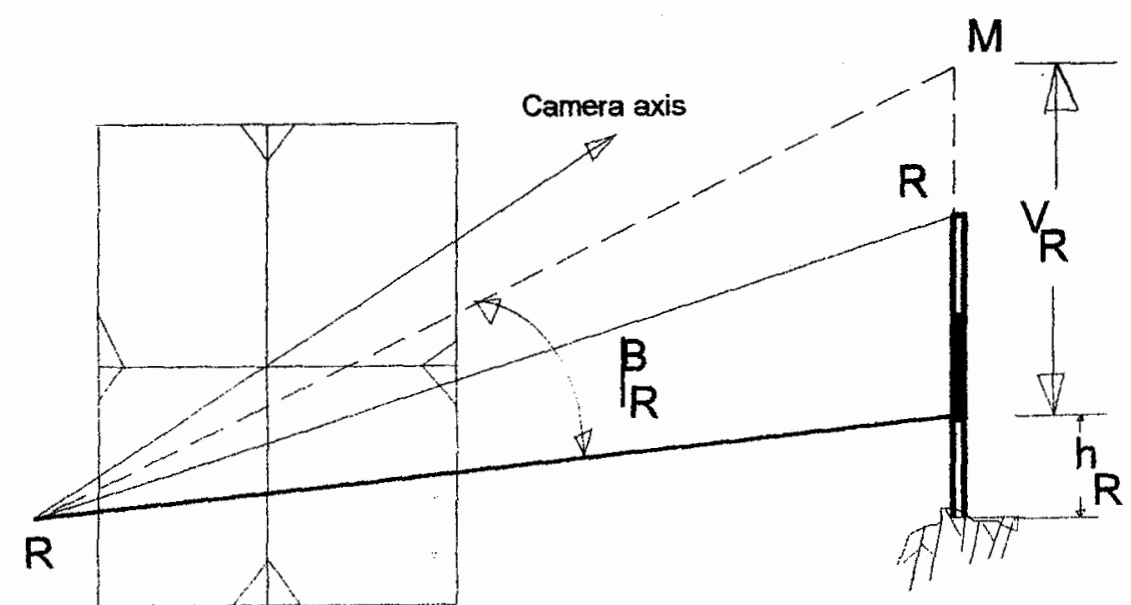

Fig. (3.c) Elevation of points at the right exposure station.

b) Both of the two photo lie on a vertical plane $\left(\omega_{1}=\omega_{2}=0.0\right)$

The translation element along the $\mathrm{Y}$-direction $\mathrm{B}_{\mathrm{Y}}$ has a zero value; because the two exposure stations lie on the $\mathrm{X}$ - axis.

The elevation of the two exposure stations ( left and right) can be calculated by using the following technique :

The philosophy of this technique is based upon photographing of one or more precise levelling staff or special constructed marker poles, (see Collins and Madge 1981) which are fixed at the appropriate places relative to the two exposures stations.

Care is taken in fixing a leveling staff, such that the base plate is at ground, and the staff should be verticaly ensured. The effect of photographing leveling is illustrated in Fig. (3.a-3.c). The photo coordinates $(x, z)$ from the center of the photography to the bottom of the staff image are recorded. Consider $\beta_{L}$ and $\beta_{R}$ being the vertical angles of inclination between the horizontal plane and the ray from the camera to the object point $P$, on the left and right photos respectively.

Then

$$
\begin{aligned}
& \beta_{L-\tan ^{-1}}\left[z /\left(x^{2}+c^{2}\right)^{0.5}\right] \\
& \text { And } \\
& \beta_{R} \tan ^{-1}\left[z^{-1} /\left(x^{-2}+c^{2}\right)^{0.5}\right]
\end{aligned}
$$

where:

$\mathrm{x}$ is the measured $\mathrm{x}$-dimension (coordinate) from the center of the photo to the image of the staff at the left station

$z$ is the measured $z$-dimension (coordinate) from the center of the photo to the image of the staff at the left station

$\mathrm{x}^{-}$is the measured $\mathrm{x}$-dimension (coordinate) from the center of the photo to the image of the staff at the right station

$z$ is the measured $z$-dimension (coordinate) from the center of the photo

to the image of the staff at the right station

According to Figure. (3.b) and Figure (3), ons can determine the difference in elevation between the camera axis at the left and right camera stations ( $V_{R}$ and $V_{R}$ ) respectively. From the photo coordinate of the lower part of the staff $(x, z)$ together with the calculated horizontal distance between the exposure stations and the vertical staff, the difference in 
elevation $\left(V_{L}\right.$ and $\left.V_{R}\right)$ between the camera axis (left and right respectively), and the lower edge of the staff graduation, can be calculated using the following equations:

$$
\begin{aligned}
& V_{L}=D_{L} \tan \left(\beta_{L}\right) \\
& V_{R}=D_{R} \tan \left(\beta_{R}\right)
\end{aligned}
$$

Where:

$V_{L}$ : is the difference in elevation between the left exposure station and the lower edge of the staff graduation

$V_{R}$ : is the difference in elevation between the right exposure station and the lower edge of the staff graduation

$\mathrm{D}_{\mathrm{L}}$ is the horizontal distance from the left camera St. to the levelling staff.

$D_{R}$ is the horizontal distance from the right camera St. to the levelling staff.

The exposure stations elevation can be obtained using the following equations:

Where

$$
\begin{aligned}
& \mathrm{E}_{\mathrm{L}}=\mathrm{V}_{\mathrm{L}}+\mathrm{h} \\
& \mathrm{E}_{\mathrm{R}}=\mathrm{V}_{\mathrm{R}}+\mathrm{h}
\end{aligned}
$$

$E_{L}$ is the elevation of the exposure station at the left station

$E_{R}$ is the elevation of the exposure station at the right station

$h$ is the elevation of the lower edge of the staff graduation.

If more than one vertical staff is available, the average value of exposure stations elevation (left and right respectively) can be obtained.

\subsection{THE OBJECT SPACE COORDINATE}

A point (P) on object is defined in terms of $3-D$ coordinates, $X, Y, Z$ while the corresponding points in the photos are in terms of their photocoordinates, $x, z$ for point $p$ on the left photos and $x^{-}, z^{-}$for point $\mathrm{p}^{-}$on the right photos. Referring to Fig. (4), consider the horizontal distance of a ground point $P$ from the left exposure station, $L P=D_{L}$. The horizontal distance of the ground point $P$ from the right exposure station, $R P=D_{R}$.

Consider $\alpha_{p}$ and $\alpha_{p}{ }^{-}$being the horizontal angle between the optical axis $\left(C A_{L} \& C A_{R}\right)$ and the ray from the camera to object point $P$ on the left and right photos respectively.

$$
\begin{aligned}
& \text { Furthermore, } \alpha_{p}=\arctan (x / c) \text { and } \alpha_{p}{ }^{-}=\arctan \left(x^{-} / c\right) \\
& \delta_{\mathrm{L}}=90-\Phi_{\mathrm{l}} \\
& \theta_{\mathrm{L}}=\delta_{\mathrm{L}}-\alpha_{\mathrm{l}} \\
& \theta_{\mathrm{I}}=90-\Phi_{\mathrm{l}}-\alpha_{\mathrm{L}} \\
& \text { \& } \\
& \delta_{\mathrm{R}}=90-\Phi_{\mathrm{R}} \\
& \theta_{\mathrm{R}}=\delta_{\mathrm{R}}-\alpha_{\mathrm{R}} \\
& \theta_{M}=180-\left(\theta_{\mathrm{L}}+\theta_{\mathrm{R}}\right) \\
& \theta_{R}=90-\Phi_{R}-\alpha_{R}
\end{aligned}
$$




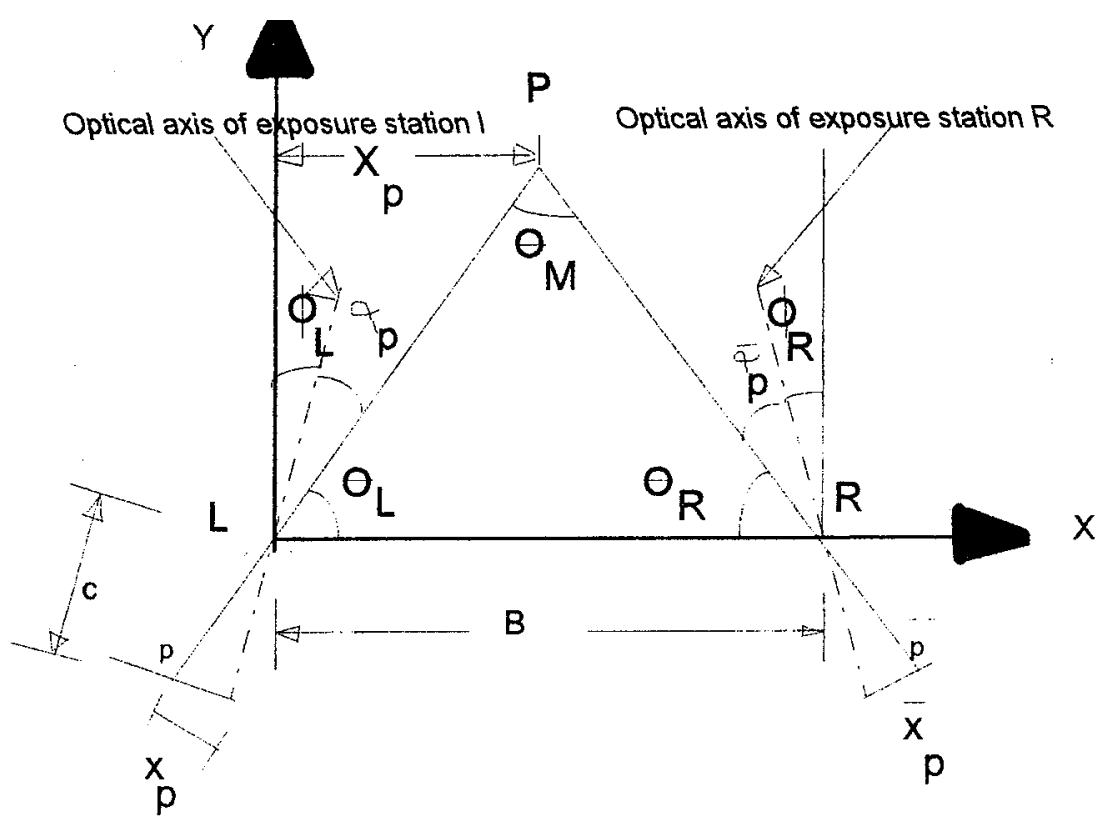

Fig. (4) Horizontal position of points from two horizontaly photos.

Consider $\theta_{L}$ and $\theta_{R}$ being the horizontal angles between the target $(P)$ and the base line at the left and right exposure stations respectively,

Then

$$
\theta_{\mathrm{L}}=\Phi_{\mathrm{L}}-\alpha_{\mathrm{L}} \quad \text { \& } \quad \theta_{\mathrm{R}}=\Phi_{\mathrm{R}}-\alpha_{\mathrm{R}}
$$

$$
\theta_{\mathrm{M}}=180-\left(\theta_{\mathrm{L}}+\theta_{\mathrm{R}}\right)
$$

Also, from sine rules in triangle L P R,

$$
\begin{aligned}
\frac{D_{L}}{\operatorname{Sin} \theta_{R}} & =\frac{B}{\operatorname{Sin} \theta_{M}} \\
\text { i.e. } D_{L} & =\frac{B \operatorname{Sin} \theta_{R}}{\operatorname{Sin} \theta_{M}} \\
\text { and also } \frac{D_{R}}{\operatorname{Sin} \theta_{L}} & =\frac{B}{\operatorname{Sin} \theta_{M}} \\
\text { i.e. } D_{R} & =\frac{B \operatorname{Sin} \theta_{M}}{\operatorname{Sin}}
\end{aligned}
$$

These give the object space coordinates:

$$
\begin{aligned}
& X_{\mathrm{P}}=\mathrm{D}_{\mathrm{I}} * \operatorname{COs} \theta_{\mathrm{I}} \\
& \mathrm{Y}_{\mathrm{P}}=\mathrm{D}_{\mathrm{I}} * \operatorname{Sin} \theta_{\mathrm{L}} \\
& \mathrm{Z}_{\mathrm{P}}=\mathrm{E}_{\mathrm{L} \text { (averagc) }}+\mathrm{D}_{\mathrm{L}} * \tan \beta_{\mathrm{I}}
\end{aligned}
$$

\subsection{THE DETERMINTION OF THE BASE LINE (B)}


The length of the base line can be obtained as follows:

-Determine the ground coordinate of the two ends of the known line

(L) by using any assumption value for (B) such as B

-Compute the ratio $(R)$ between the true length of the known line $(L)$ and the calculated length of the same known line $\left(L^{-}\right)$, which was calculated from the ground coordinates.

-Compute the correct value of the base line (B) as follows:

The correct value $(\mathrm{B})=\mathrm{B}^{-} *(\mathrm{R})$

$$
\operatorname{Ratio}(R)=\frac{\text { True length of the known line }(L)}{\text { Computed length of the known line }\left(L^{-}\right)}
$$

\subsection{CHECK COMPUTATION OF THE OBJECT SPACE COORDINATES}

According to figure (4), the object space coordinates can be determined as a check computation using the following equations:

$$
\begin{aligned}
& X_{P}=B-\left(D_{R} * \operatorname{COs} \theta_{R}\right) \\
& Y_{P}=D_{R} * \operatorname{Sin} \theta_{R} \\
& Z_{P}=E_{R(\text { average) }}+D_{R} * \tan \beta_{R}
\end{aligned}
$$

\section{THE EXPERIMENTAL WORK}

In this research, a test field has been successfully used for experimental work. The test field was photographed with the metric UMK 10/1318 from Zeis Jena. The elevation view of the test field is shown in figure (1).

Two stereo pairs were so arranged, that they were on the same base and also one base-to object distance ratio is used. The first stereo pair is performed horizontal in a symmetrical convergent imaging with $29^{\circ}$ convergent angle, and the second stereo pair is established also horizontal in a symmetrical convergent imaging with $43^{\circ}$ convergent angle. In the photography, two precise leveling staff in a vertical position and a subtence bar were used. The leveling staves and the subtence bar are 2 meters long and they were lying in front of the test field. All the photographs were measured with the stereo comparator, Techochart- D from Carl Zeis Jena. The photo coordinates were measured with a coordinates RMS of $5 \mu \mathrm{m}$. Image coordinates for each individual fiducial marks of the two photos were measured twice.

\section{DATA REDUCTION}

In this work, the data reductions have been done with two different analytical approaches to determine the ground coordinates of points of interest: the virtual image method and the suggested approach. 
In this method, the mathematical photogrammetric models (such as relative and absolute orientations)are applied to theodolite images which are formed analytically from theodolite measurements.

\subsection{THE PROPOSED APPROACH}

In this approach, no control points have been used. The data reduction procedure consists of:

a) The determination of the horizontal angles $\left(\alpha_{\mathrm{L}}\right.$ and $\left.\alpha_{\mathrm{R}}\right)$ between the optical axis and the ray from the camera to object point $P$, on the left and right photo respectively;

b) Determination of the vertical angles $\left(\beta_{L}\right.$ and $\left.\beta_{R}\right)$ between the horizontal plane and the ray from the camera to object point $\mathrm{P}$, on the left and right photo respectively;

c) Computation of the horizontal angles $\left(\theta_{\mathrm{L}}\right.$ and $\left.\theta_{\mathrm{R}}\right)$ between the object point $P$ and the base line at the left and right exposure stations respectively;

d) Calculation of the horizontal distances $\left(D_{L}\right.$ and $\left.D_{R}\right)$ between the object point $\mathrm{P}$, and the left and right exposure station respectively , and

e) Computation of the coordinates $(X, Y$ and $Z$ ) of points of interest.

\section{DISCUSSION OF THE RESULTS}

The coordinates which are computed from the virtual image method and the suggested approach are compared by the RMS- values of the coordinate differences in the check points. The comparison of results between the suggested technique and the virtual image method is shown in table (1) in terms of $X, Y, Z$ coordinates differences as well as their essentially statistical parameters (RMS)

From table(4), it can be seen that, the virtual image method gives more accurate results than the suggested approach, since the former yields a smaller RMS than the latter.

Regarding to the comparison between the virtual image method and the suggested approach, the following remarks can be stated

The photographs contain a wealth of interpretable information; thus one can say that, the photogrammetric archives of the building assume an "intellecula! conservation" of the building in its "effective shape", at a precise moment in its history, but The virtual image method takes no account of perspectie but simply shows details and parts geometrically. 
The proposed technique provides information for a very large number of points at a short time. This advantage is very essential, in case of structures, having rapid movements or deformations. This is the case, since the virtual image method takes more time to collect the necessary measurements at a certain time, during which the different monitoring defined targets could have gained a quite movement, not coinciding with the measurement instance.

The virtual image method provide information on movement at only a little number of targets on the object.

By using the proposed technique, a permanent record can be taken of a very large number of monitoring target points.

TABLE (4): STATISTICS OF OBTAINED COORDINATE DIFFERENCES FOR THE SECOND MODEL BETWEEN THE CONVENTIONAL AND THE PROPOSED TECHNIQUES AT THE USE CHECK POINTS (IN mm)

\begin{tabular}{|c|c|c|c|c|c|c|}
\hline \multirow[t]{2}{*}{$\begin{array}{l}\mathrm{Pt} \\
\text { No }\end{array}$} & \multicolumn{3}{|c|}{$\begin{array}{c}\text { THE PROPOSED } \\
\text { TECHNIQUE }\end{array}$} & \multicolumn{3}{|c|}{ the pseudo image } \\
\hline & $\Delta \mathrm{X}$ & $\Delta Y$ & $\Delta \mathrm{Z}$ & $\Delta \mathrm{X}$ & $\Delta \mathrm{Y}$ & $\Delta Z$ \\
\hline 1 & 1.30 & 1.54 & 1.26 & 0.8 & 1.4 & 0.7 \\
\hline 2 & 1.38 & 1.22 & 1.40 & 0.8 & 1.4 & 0.6 \\
\hline 3 & 1.48 & 1.14 & 1.29 & $\overline{0.8}$ & 1.4 & 0.8 \\
\hline 4 & 1.18 & 1.17 & 1.08 & 0.7 & 1.4 & 0.5 \\
\hline 5 & 1.24 & 1.21 & 1.36 & 0.7 & 1.4 & 0.7 \\
\hline 6 & 1.27 & 1.2 & 1.39 & 0.7 & 1.4 & 0.6 \\
\hline 7 & 1.14 & 1.14 & 1.51 & 0.5 & 1.4 & 0.4 \\
\hline 8 & 1.98 & 1.6 & 1.16 & 0.5 & 1.4 & 0.7 \\
\hline 9 & 1.57 & 1.16 & 1.18 & 0.5 & 1.4 & 0.8 \\
\hline 10 & 1.28 & 1.19 & 1.14 & 0.9 & 1.4 & 0.6 \\
\hline 11 & 1.32 & 1.27 & 1.30 & 0.8 & 1.4 & 0.8 \\
\hline 12 & 1.14 & 1.21 & 1.36 & 0.9 & 1.4 & 0.7 \\
\hline 13 & 1.54 & 1.58 & 1.17 & 0.6 & 1.76 & 0.8 \\
\hline 14 & 1.04 & 1.41 & 1.12 & 0.6 & 1.92 & 0.8 \\
\hline 15 & 1.08 & 1.42 & 1.23 & 0.5 & 1.28 & 0.6 \\
\hline 16 & 1.86 & $1 . \overline{74}$ & 1.58 & 0.5 & 1.4 & 0.6 \\
\hline 17 & 0.99 & 1.28 & 1.26 & 0.6 & 1.4 & 0.5 \\
\hline 18 & 1.38 & $1 . \overline{42}$ & 1.38 & 0.6 & 1.4 & 0.5 \\
\hline 19 & 1.39 & 1.46 & 1.32 & 0.6 & 1.50 & 0.4 \\
\hline 20 & 1.48 & 1.44 & 1.18 & 0.6 & 1.4 & 0.5 \\
\hline 21 & 1.48 & 1.4 & 118 & 0.6 & 1.5 & 0.5 \\
\hline 22 & 1.48 & $1 .+4$ & 1.18 & 0.7 & 1.92 & 0.6 \\
\hline 23 & 1.48 & $1 .+4$ & 1.18 & 0.6 & 1.82 & 0.7 \\
\hline RMS2 & 1.36 & 1.35 & 1.27 & 0.570 & 1.57 & 0.378 \\
\hline
\end{tabular}


The previous illustration for the virtual image method and the proposed technique shows that:

In matter of cost, the proposed technique permitted substantial savings in time and effort compared with the pseudo image.

The proposed technique has a large capacity and quite good accuracy. It is preferable to use the proposed technique when a great number of targets to be measured in a short space of time.

The pseudo image method can be used only when a little number of points has to be measured.

\section{REFERENCES}

Abdel-Aziz,Y.,I.,1979, An application of photogrammetric techniques to building construction .Photogrammetric Engineering and Remote Sensing

Abdel- Gawad, A.K. (1994) " The Application of High precise Surveying Technique in Measuring Deformations of Structures" M.Sc. Thesis, Faculty of Engineering, Ain Shams University.

Amin,E.,A (1987)" Deformation measurement by photogrammetry "Ph.D Thesis, University of London, England.

Behairy, A. M. and Zahran, M.I.,(1990) "Reliability for Close Range Photogrammetry " Proceeding of the First Conference on Civil Eng., Volume 2, Military Technical College.

Carbonnel,M. and Dallas,R.W.,1985 The International Committee for Architectural Photogrammetry

(CIPA)

Aims,Achievements,Activities. Photogrammetria,40(2): 193-202.

Clarke,T.,1990," The use of optical triangulation for high speed acquisition of cross section or profiles of structures", Phtogrammetric Record, 13,(76),pp. 523-532.

Collins.B.J. and Madge B. 1981" Photo- radiation: New method for monitoring Beach Movement. Charteared Land Survey Chartered Minerals surveyors, Vol. 3(1), pp.(4-11)

Cooper,M.A., and Robson,S., 1990, "High precision photogrammetric monitoring of the deformation of a Steel Bridge" Phtogrammetric Record, 13,(76),pp. 505-510.

Ebner, Fristsch and Heipke 1991 Digital photogrammetric systems. Wichmann verlag

El-Komy, A. 1989 " Evaluation of two surveying methods for measuring deformation", M.Sc. thesis, Cairo University, Cairo.

El-Hoseny M., 1993 " An Algorithm for high accuracy surveying in engineering structures and industrial sites". Engineering Bulletin, Vol.28, NO.1, Ain Shams University, Cairo

Frei,A and Scherrer,1992, "Use of the Global positioning System in Dam deformation and Engineering surveys", Leica AG.,Herrbrug,Switzerland.

Gosh.S., 1988, "Analytical photogrammetry"Pergman press., New York. 
Hottier,p.H.(1976) : “ Accuracy of close-Range Analytical restitution: practical experiments and prediction" Photogrammetric Engineering and Remote sensing, Vol.42,No.3,March 1976, pp. $345-375$.

Karara, H., M. 1989 Non - topographic photogrammetry American Society for photogrammetry and remote sensing.

Mofitt,F.H and Mikhail, E. ,1980, "Photogrammetry" Harper\&Row. Publishers, New York.

Rahil, A.M. (1997) "A Comparative Study of Different Configuration Systems in Close-Range Photogrammetry" Civil Engineering Research Magazine EL-AZhar Univ., Vol. (19), No.5, 1997

Rahil, A.M. (2000) "An Alternative Approach for Solving the Space Intersections Problem in Close- Range Photogrammetry" Engineering Research Bulletin, Vol.23,No 3,2000 Minufiya University, Faculty of Engineering, Shebien El-Kom, Egypt.

Rashad El-Din M.M.;Atia K. and Mahfoud, N.Y. (1997): "Accuracy in positioning of new stations in horizontal control networks" Alexandria Engineering jornal, Vol. 36, No 5. 1997, Alexandria,Egypt.

Von Gelder, B.H., 1994, "Geodetic Control Survey: Lecture Notes ", Purdue University, Civil Eng. Dep., West Lafayette, IN., USA

Wester-Ebbinghause, W.,1980 Numerische Verfahren fur die Architekturphotogrammetrie. International Archives of photogrammetry,XXIII (B5):813-823 


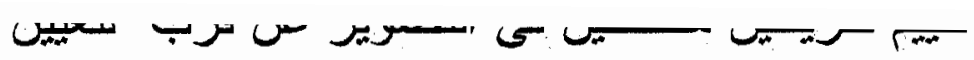

الأبعاد الثالاثية كتطبيق للتحقق من الر أسية

فى هذا البحث تم مناقشة طريقتين مختلفتين كما تم أيضا المقارنة بين هاتين الطريقتين فى التصوير عن ثرب (Close Range Photogrammetry) بهدف تحديد أى الطريقتين الأفضل من ناحية الاقة و الأسهل فى التتفيذ و الأكثر إقتصادية . وقد ثمت المفاضلة من خلال مقارنة الإحداثيــات فىكلا الطريقتين بالإحداثيات المعينة في حقــــلـ الإختبــار بالتقـــاطع

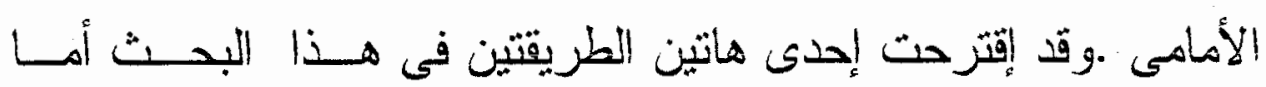
الطريقة الثانية فتعرف بالصور الز ائفة. وقد نم فى هذا البحث التوصل الىى النتائج الآتية :

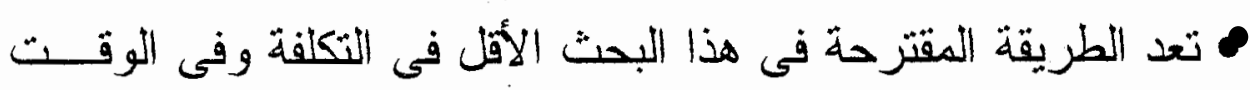
و المجهود اللازم للتفيذ بالمقارنة بطريقة الصور الزائفة. الطريقة المقترحة تؤدى إلى نتائج جيدة ويفضل إستخدامها فى حالة الأنقط الكثبرة و الوقت القصبر ل • يفضل إستخدام طريقة الصور الزائفة فى حالة النقط القبلة و الوقت الطويل 